\title{
ALGUNAS CONSIDERACIONES SOBRE EL DERECHO A LA INTIMIDAD PERSONAL Y FAMILIAR DE LOS PRESOS EN LOS CENTROS PENITENCIARIOS
}

\author{
LUIS E. DELGADO DEL RINCÓN \\ Profesor Titular de Derecho Constitucional \\ Universidad de Burgos
}

\begin{abstract}
SUMARIO
I. Introducción: La reducción de la intimidad de los presos al ámbito de la vida interior.

II. La legislación penitenciaria y el derecho a la intimidad personal y familiar de los presos. Una regulación legal insuficiente.

III. El derecho a la intimidad y el principio celular o de alojamiento en celda individual.

IV. El derecho a la intimidad corporal de los presos como manifestación de la intimidad personal.

V. El derecho a la intimidad de los presos en sus relaciones con el exterior a través de un sistema de visitas y comunicaciones.
\end{abstract}

\section{INTRODUCCIÓN: LA REDUCCIÓN DE LA INTIMIDAD DE LOS PRESOS AL ÁMBITO DE LA VIDA INTERIOR}

El art. 25.2 de la Constitución española dice que las personas que estuvieren cumpliendo una pena de prisión gozarán de los derechos y libertades fundamentales del capítulo segundo del título primero, salvo que expresamente hayan sido limitados por: "el contenido del fallo condenatorio, el sentido de la pena y la Ley penitenciaria".

La ejecución de la pena privativa de libertad a la que ha sido condenada una persona va a suponer para ésta la pérdida del derecho "matriz": el de su li- 
bertad personal. La privación de este derecho fundamental no implica la supresión de la titularidad y del ejercicio de los demás derechos, de ahí la dicción del art. 25.2 CE, aunque sí conllevará, precisamente por la naturaleza de la pena impuesta y por la "fuerza expansiva" de la pérdida de libertad, la restricción de otros derechos y libertades del preso. Dicho de otro modo, el ingreso en prisión del condenado a una pena privativa de libertad para su cumplimiento y las condiciones particulares inherentes a la vida en prisión, darán lugar a una modificación del status libertatis del recluso, ya que a partir de entonces quedará sujeto a un estado de libertad restringida y a una limitación de algunos de sus derechos y libertades. Limitación que viene determinada por la consecución de determinados fines públicos por la Administración penitenciaria como la retención y custodia de los detenidos presos y de los penados (art. 1 LOGP) o el mantenimiento de la seguridad y del buen orden del establecimiento penitenciario (arts. 18, 26.d, 29.2, 41.1... LOGP) ${ }^{1}$.

Sin duda alguna, uno de los derechos fundamentales que con mayor intensidad va a verse afectado por el internamiento de una persona en un centro penitenciario va a ser el derecho a la intimidad personal y familiar del art. 18.1 $\mathrm{CE}$. Y es que, como ha señalado el Tribunal Constitucional, una de las consecuencias más dolorosas de la pérdida de la libertad es la reducción de lo íntimo casi al ámbito de la vida interior ${ }^{2}$.

La reducción de la intimidad es, pues, uno de los costes elementales derivados del ingreso en prisión, en cuanto que este hecho conduce, por sí mismo, a la exposición del preso y de su vida íntima ante las demás personas que se encuentran en su situación y ante los funcionarios encargados de su vigilancia y custodia. Disminución de la intimidad que, además, se verá incrementada por otras circunstancias como la situación de hacinamiento en que se encuentran la mayor parte de las cárceles en nuestro país, o el sometimiento de los reclusos, desde el momento en que ingresan en prisión, a un control exhaustivo de su vida por parte de la Administración penitenciaria.

Por su relación estrecha con el derecho a la intimidad del art. 18 CE, los presos pueden ver limitados también los derechos reconocidos en los siguientes apartados del citado precepto constitucional: el derecho a la inviolabilidad del domicilio (que constituye la esfera espacial en la que se desarrolla la vida personal y familiar del titular del derecho a la intimidad); el derecho al secreto de las comunicaciones (que permite controlar la divulgación de todo aquello que es íntimo, impidiendo que sea conocido por terceros sin el consentimiento del comunicante) y el derecho a la autodeterminación informativa sobre el

1 En general, sobre las limitaciones de los derechos fundamentales de los reclusos, vid., entre otros, los siguientes trabajos: GONZÁLEZ NAVARRO, F., "Poder domesticador del Estado y derechos del recluso", en Estudios sobre la Constitución española. Homenaje al profesor Eduardo García de Enterría, vol. II, Madrid, 1991, pp. 1117 y ss.; GARCÍA MORILLO, J., "Los derechos fundamentales de los internos en centros penitenciarios", Revista Poder Judicial, n. ${ }^{\circ}$ 47, 1997, pp. 23 y ss. y ABA CATOIRA, A., La limitación de los derechos fundamentales por razón del sujeto. Los parlamentarios, los funcionarios y los reclusos, Madrid, 2001, pp. 239 y ss.

2 Cfr. la STC 89/1987, de 3 de junio (FJ 2. ${ }^{\circ}$ ). 
tratamiento automatizado de datos de carácter personal (en cuanto que la informatización de los datos personales puede entrañar una seria amenaza contra el derecho a la intimidad).

Estos derechos, a pesar de gozar de autonomía propia, van a tener también un carácter instrumental respecto del derecho a la intimidad, ya que constituirán una garantía fundamental para proteger la existencia de un ámbito propio, reservado y exclusivo de la persona ${ }^{3}$, incluso aunque ésta se halle privada de libertad. Y es que el derecho a la intimidad se configura también como un derecho que está estrechamente vinculado con el libre desarrollo de la propia personalidad ${ }^{4}$ y con la dignidad de la persona humana que, como principio esencial de nuestro ordenamiento constitucional, sirve de fundamento a todos los derechos y libertades, según lo dispuesto en el art. 10.1 CE.

Así, con carácter general y de acuerdo con la doctrina expuesta por el Tribunal Constitucional, el derecho a la intimidad es un "derecho personalísimo ligado a la misma existencia del individuo" que tiene por objeto garantizar "la existencia de un ámbito propio y reservado frente a la acción y conocimiento de los demás, necesario — según las pautas de nuestra cultura - para mantener una calidad mínima de la vida humana ${ }^{5}$. Es, por tanto, este ámbito vital propio, exclusivo y reservado al conocimiento e intromisiones de los demás (ya sean particulares o poderes públicos) lo que constituye el objeto principal sobre el que va a recaer la protección constitucional del derecho a la intimidad personal y familiar.

Estamos, pues, ante un derecho de difícil definición, ante un derecho dinámico, contingente y de delimitación casuística, en el que existen ciertas dificultades a la hora de determinar la intimidad como bien jurídico protegido por el derecho, o a la hora de establecer qué acciones de terceros pueden considerarse intromisiones ilegítimas. Labor que, atendiendo a las circunstancias del caso concreto, corresponderá a los órganos judiciales y al Tribunal Constitucional, en vía de amparo ${ }^{6}$.

3 Así, por ejemplo, para RODRÍGUEZ RUIZ, B., El secreto de las comunicaciones: tecnología e intimidad, Madrid, 1998, pp. 23 y ss., el derecho a la intimidad conforma "un telón de fondo" respecto del derecho al secreto de las comunicaciones, de tal modo que aquél podría resurgir cuando por alguna razón este último no pudiera invocarse. MATIA PORTILLA, F. J., El derecho fundamental a la inviolabilidad del domicilio, Madrid, 1997, pp. 46 y ss., pone de manifiesto cómo la intimidad constituye el bien jurídico que protege la inviolabilidad del domicilio.

4 Tradicionalmente, la intimidad se ha venido considerando como un derecho de la personalidad. Cfr. al respecto, DE CUPIS, A., I diritti della personalità, Milán 1982, p. 257.

5 Vid. la STC 231/1988, de 2 de diciembre (FJ 3. ${ }^{\circ}$ ).

6 Sobre las nociones de "intimidad", "privacidad" y "vida privada" como bien jurídico protegido por el derecho a la intimidad, pueden consultarse, entre otros, los siguientes trabajos: MARTÍNEZ DE PISÓN CAVERO, J., El derecho a la intimidad en la jurisprudencia constitucional, Madrid, 1993, pp. 80 y 81; RUIZ MIGUEL, C., La configuración constitucional del derecho a la intimidad, Madrid, 1995, p. 29; LUCAS MURILLO DE LA CUEVA, P., "El derecho a la intimidad", en Estudios de Derecho Público. Homenaje a Juan José Ruiz-Rico, vol. I, Madrid, 1997, pp. 498-506; MATIA PORTILLA, F. J., "Constitution et secret de la vie privée: Espagne", Annuaire International de Justice Constitutionnelle, XVI, 2000, pp. 210 y 211; REBOLLO DELGADO, L., El derecho fundamental a la intimidad, Madrid 2000, pp. 83, 85 y 224 y MIERES MIERES, L.J., Intimidad Personal y Familiar. Prontuario de Jurisprudencia Constitucional, Pamplona, 2002, pp. 33 у 34. 
Las dificultades anteriores aumentan en el caso de las personas recluidas en un centro penitenciario, ya que, en este ámbito, y precisamente por estar vinculado con la libertad personal, la extensión y limitaciones del derecho a la intimidad van a depender de diversos factores como la clasificación del interno (primero, segundo y tercer grado), el tipo de régimen penitenciario (ordinario, abierto o cerrado) o los cambios que puedan sucederse en los criterios de clasificación (progresión o regresión de grado).

De este modo, las limitaciones que puedan recaer sobre el derecho a la intimidad personal y familiar de los reclusos de primer grado que, por su peligrosidad extrema, se hallen internos en un establecimiento de régimen cerrado, donde las medidas de control y seguridad son más estrictas, no serán de la misma entidad que las de aquellos otros que, por sus circunstancias personales y penitenciarias, han sido clasificados de tercer grado, encontrándose en un establecimiento de régimen abierto, en el que pueden desarrollar un modo de vida en semilibertad ${ }^{7}$.

\section{LA LEGISLACIÓN PENITENCIARIA Y EL DERECHO A LA INTIMIDAD PERSONAL Y FAMILIAR DE LOS PRESOS: UNA REGULACIÓN LEGAL INSUFICIENTE}

La Ley Orgánica General Penitenciaria de 1979 no contiene una regulación específica del derecho a la intimidad personal y familiar de los presos. Es más, este derecho ni tan siquiera aparece mencionado expresamente en el Título Preliminar de la Ley, donde sí se enumeran algunos de los derechos de los que son titulares los reclusos. Sin embargo, no existe duda alguna para afirmar que dicho derecho ha de entenderse incluido en el art. 3 LOGP, cuando - de acuerdo con lo dispuesto en el art. 25.2 CE - se proclama genéricamente que la actividad penitenciaria se ejercerá respetando los derechos e intereses jurídicos de los recluidos, quienes, en consecuencia, podrán ejercitar los derechos civiles, políticos, sociales, económicos y culturales, siempre que no fuesen incompatibles con el objeto de su detención o el cumplimiento de la condena ${ }^{8}$.

El Reglamento Penitenciario de 1996, en su Exposición de Motivos (parágrafo II, apartado d), comienza ya haciendo referencia a la intimidad, cuando

7 Asimismo, dentro de los tipos de establecimientos de régimen abierto, será en las denominadas Unidades Dependientes (arts. 80.4 y 165 a 167 RP) donde los reclusos gozarán de un status de libertad más amplio y, por tanto, las limitaciones a sus derechos, entre los que está el derecho a la intimidad, serán de menor entidad.

8 A pesar de lo manifestado, la Ley alude expresamente a la intimidad en dos preceptos: el art. 38.3, cuando establece que las visitas de los menores de diez años que no convivan con la madre en el centro penitenciario habrán de realizarse «sin restricciones de ningún tipo en cuanto a frecuencia e intimidady; y el art. 51, cuando regula el régimen de comunicaciones de los internos con sus familiares, amigos y representantes acreditados de organismos e instituciones de cooperación penitenciaria, al exigir que dichas comunicaciones habrán de celebrarse de forma que se urespete al máximo la intimidad". 
enumera algunas de las novedades introducidas en dicha norma. Así, en lo que concierne al régimen penitenciario, destaca "la nueva regulación de materias que afectan al derecho a la intimidad de los reclusos como la protección de los datos de carácter personal contenidos en los ficheros penitenciarios y la recepción de la doctrina del Tribunal Constitucional sobre comunicaciones con los abogados defensores y sobre la forma de realizar los cacheos personales $"$. No obstante, es en el Título I, capítulo II, "relativo a los derechos y deberes de los internos", donde en su art. 4.2 b) se regula expresamente el derecho a la intimidad $^{10}$.

En algunos casos, la inexistencia o insuficiencia de normas legales o reglamentarias ha hecho que surjan unas normas penitenciarias paralelas, de ámbito exclusivamente administrativo y de difuso control jurisdiccional, ya que no son publicadas oficialmente. Se trata de las Circulares e Instrucciones de la Dirección General Penitenciaria (DGIP), que son concebidas como «meras directrices internas de servicio", pero que por su carácter inequívoco de disposición general y por afectar directamente a sujetos no integrados en la organización administrativa — los internos- deberían recogerse, cuando menos, en el Reglamento Penitenciario ${ }^{11}$.

Con independencia de la escasa mención que se hace al derecho a la intimidad personal y familiar de los presos en la legislación penitenciaria — del todo punto insuficiente en la LOGP-, hay que reconocer que, a lo largo del ar-

9 Aspectos que desarrolla a lo largo de su articulado: la protección de los datos de carácter personal, en el cap. III, del Tít. I (arts. 6 a 9); el régimen de comunicaciones y visitas, en la secc. 1. ${ }^{a}$, del cap. IV, del Tít. II (arts. 41-49, en particular, el relativo a los abogados defensores, art. 48) y el modo de realizar los cacheos y registros, en el art. 68.

10 En este precepto - que por su contenido habría de estar ubicado en la LOGP - se conecta la intimidad con la dignidad personal y con la identidad del preso: los internos tendrán "derecho a que se preserve su dignidad, así como su intimidad, sin perjuicio de las medidas exigidas por la ordenada vida en prisión. En este sentido, tienen derecho a ser designados por su propio nombre y a que su condición sea reservada frente a terceros".

11 La proliferación de este tipo de normas ha sido criticada por la doctrina, ya que, en algunos casos, bajo la invocación del interés público relativo al mantenimiento del orden y de la seguridad del centro, se ha procedido a una regulación más restrictiva, si cabe, del ya considerablemente limitado (por la Ley y el Reglamento) status libertatis del preso. Baste citar, a título de ejemplo, la regulación restrictiva que sobre el régimen cerrado se llevó a cabo por la DGIP en la Circular de 2 de octubre de 1991 y en la Instrucción de 28 de febrero de 1995, ambas derogadas por la Instrucción 24/1996, de 16 de diciembre, que procede a la refundición, armonización y adecuación de las circulares, instrucciones y órdenes de servicio en materia de régimen y seguridad, con el objeto de coordinar y completar las normas de control y prevención establecidas en el Reglamento Penitenciario. Las Circulares e Instrucciones de la DGIP se pueden consultar en la página web del Ministerio del Interior, dentro de la sección de Instituciones Penitenciarias, en su apartado de Circulares e Instrucciones: $\{h t t p: / w w w . m i r . e s /$ instpeni/instrucciones/ instrucciones. $h t m\}$. Una crítica doctrinal a estas normas puede verse en los siguientes trabajos: TAMARIT SUMALLA, J.-M., GARCÍA ALBERO, R., SAPENA GRAU, F. y RODRÍGUEZ PUERTA, M., Curso de Derecho penitenciario, Valencia, 2001, pp. 197-198 y, sobre todo, el trabajo de AYMERICH CANO, C. I., «Régimen cerrado y cárceles de máxima seguridad. Una reflexión desde el Derecho Administrativo", publicado en @dministración, Ciberrevista de Derecho Administrativo, n. ${ }^{\circ}$ 10, 1999: \{http: www.law.unican.es ladministración/ estu/ 99003t.htm\}. 
ticulado de la LOGP y del RP, se regulan diversas materias relacionadas con la organización, el régimen, el tratamiento o actividades penitenciarias que incidirán directa o indirectamente sobre la intimidad personal y familiar de los reclusos. El análisis de estas materias nos permitirá conocer la extensión o alcance del contenido del derecho a la intimidad de los presos.

$\mathrm{Si}$ bien son muy numerosos los supuestos que en el ámbito penitenciario pueden afectar al derecho a la intimidad de los presos, nos centraremos en aquellos casos que han llegado hasta el Tribunal Constitucional, para conocer la doctrina jurisprudencial fijada por este órgano en materia de derecho a la intimidad de los reclusos. Para ello, seguiremos el siguiente orden: la intimidad del preso en su celda de alojamiento, la intimidad corporal del interno frente a la práctica de determinadas medidas de seguridad interior (los cacheos con desnudo integral) o frente a la asistencia médica obligatoria y la intimidad del recluso en el régimen de visitas y comunicaciones.

\section{EL DERECHO A LA INTIMIDAD Y EL PRINCIPIO CELULAR O DE ALOJAMIENTO EN CELDA INDIVIDUAL}

Uno de los principios orientadores del sistema penitenciario que van a incidir sobre el derecho a la intimidad de los presos es el denominado principio celular o de alojamiento en celda individual. Dicho principio se recoge en la legislación penitenciaria, en el art. 19 LOGP, al afirmar que: “todos los internos se alojarán en celdas individuales". Sin embargo, a renglón seguido, este precepto introduce algunas excepciones al citado principio que disvirtúan su declaración. Así se dice que podrá recurrirse a "dependencias colectivas", mediante una selección adecuada de los internos, en casos de insuficiencia temporal de alojamiento o por indicación del médico o de los equipos de observación o tratamiento".

El art. 13 RP regula el principio celular en términos similares a la norma legal mencionada, si bien añade algunos matices en relación con los supuestos legales de alojamiento en dependencias colectivas. Así, dispone que puede alojarse en una celda a más de una persona, "preservando la intimidad", cuando las dimensiones y habitabilidad de la celda lo permitan, y siempre que el hecho de compartir la celda se haya solicitado por el interno y que no existan urazones de tratamiento, médicas, de orden o de seguridad que lo desaconsejen". Asimismo, el párrafo $3 .^{\circ}$ del art. $13 \mathrm{RP}$, admite la posibilidad de que existan dormitorios colectivos en los establecimientos especiales y de régimen abierto.

La previsión legal del principio celular tiene por finalidad facilitar a los internos un espacio físico, aunque sea mínimo, para que, durante algunos momentos del día, éstos puedan aislarse en su celda de los demás reclusos, disfrutando de una mayor intimidad de la que tendrían en dependencias colectivas. De ahí que la celda se convierta en el reducto principal de la intimidad de los presos. Asimismo, este principio celular encuentra su fundamento en la necesidad de respetar la personalidad y la dignidad humana de los reclusos. 
La cuestión que cabe plantearse en este momento es si el alojamiento en celda individual constituye un derecho del preso y si este derecho forma parte integrante del contenido del derecho a la intimidad personal. Dicho de otra manera, si el hecho de que la Administración penitenciaria obligue a uno o varios reclusos a compartir la celda con otros, fuera de los casos expresamente previstos en la legislación penitenciaria, vulneraría o no su derecho a la intimidad personal.

A esta cuestión se ha referido el Tribunal Constitucional en la STC 195/1995, de 19 de diciembre (aunque sin llegar a todas sus consecuencias), con ocasión de la interposición de un recurso de amparo por parte de un preso que invocaba, entre otros, la vulneración del derecho a la intimidad personal del art. $18.1 \mathrm{CE}$, al entender que la Administración penitenciaria había infringido lo dispuesto en el art. $15 \mathrm{RP}$ anterior (regulador del principio celular). A juicio del recurrente, se le obligaba a compartir una celda con otro interno fuera de los supuestos previstos en la legislación penitenciaria. Ante las protestas del interno, la Administración penitenciaria le incoa un expediente disciplinario del que resulta la imposición de una sanción por falta grave. La decisión administrativa sancionatoria será recurrida por el interno ante el Juzgado de Vigilancia Penitenciaria, que la confirmará mediante la correspondiente sentencia.

El Tribunal Constitucional, compartiendo las tesis del Ministerio Fiscal y del Abogado del Estado ${ }^{12}$, considera que la obligación impuesta al recurrente en amparo por la Administración Penitenciaria de compartir su celda con otro recluso no constituye la lesión del art. 18.1 CE, entre otras razones, porque, aunque sea cierto que tanto el art. 19.1 LOGP como el art. $15 \mathrm{RP}$ uestablecen con carácter general que cada interno ocupará una celda individual", no es menos cierto que dichas normas admiten también "la posibilidad de convivencia de varios internos en la misma celda por insuficiencia temporal de alojamiento u otras razones, sin que por ello hayan de considerarse vulnerados los mencionados preceptos de la legislación penitenciaria, que no consagran un derecho subjetivo a habitación o celda individual, tal y como parece pretender el recurrente".

El Tribunal Constitucional añade además, invocando jurisprudencia anterior en materia penitenciaria, que dicho derecho tampoco puede extraerse directamente del art. 18.1 CE, pues uuna de las consecuencias más dolorosas de la privación de libertad es la reducción de la intimidad de quienes la sufren, de tal manera que sólo podrán ser consideradas lesivas de la intimidad aquellas medidas que la reduzcan más allá de lo que la ordenada vida en prisión requiera

12 El Ministerio Público en su escrito de alegaciones estimaba que la convivencia de dos internos en la misma celda no afecta al contenido del derecho a la intimidad, ya que el art. 15 RP autoriza dicha convivencia cuando exista una causa que la justifique, como puede ser la insuficiencia temporal de alojamiento; considerando además que la protesta del interno se debe, no al hecho de compartir su celda, sino a compartirla con una persona desconocida. El Abogado del Estado entiende que de los arts. 18.1 CE y $15 \mathrm{RP}$ no deriva derecho alguno del interno a impedir que se habilite una habitación colectiva, ni tampoco a negarse a compartir la celda con otro recluso. 
(SSTC 89/1987 y 57/1994), requisito que no concurre en el presente caso pues, como ya se ha puesto de manifiesto, la propia legislación penitenciaria prevé en determinados supuestos la posibilidad de celdas compartidas" ${ }^{13}$.

En definitiva, para el Tribunal Constitucional, conforme a lo dispuesto en la Ley penitenciaria, no existe un derecho subjetivo, un derecho de configuración legal de los internos de alojamiento en celda individual, ni tampoco éste forma parte integrante del contenido del derecho fundamental a la intimidad personal de los reclusos.

Ahora bien, conviene indicar que debido a la situación real de masificación en la que se encuentran la mayor parte de nuestros establecimientos penitenciarios, lo que debiera ser excepcional, el alojamiento colectivo de los reclusos, pasa a ser la regla general. En esta situación, «la insuficiencia temporal de alojamiento" se convierte en permanente y constituye un motivo legal para que la Administración penitenciaria justifique siempre el alojamiento en celda colectiva de los reclusos, vaciando, en la práctica, el contenido del principio celular o de alojamiento en celda individual que la ley atribuye al preso $^{14}$.

13 Cfr. el FJ 3. ${ }^{\circ}$ de la STC 195/1995, de 19 de diciembre. DUQUE VILLANUEVA, J., “El derecho a la intimidad personal y familiar en el ámbito penitenciarion, en el monográfico sobre Perfiles del derecho constitucional a la vida privada y familiar (dir. de J.J. López Ortega), Cuadernos de Derecho Judicial, vol. XXII, CGPJ, Madrid, 1997, pp. 121-122, apunta, en la línea seguida por el Tribunal Constitucional, que no puede inferirse como contenido del citado derecho fundamental en el ámbito penitenciario el derecho de los internos a alojarse en celdas individuales..., del mismo modo que tampoco "cabe inferir del contenido del derecho a la intimidad (...), o de la garantía a la inviolabilidad del domicilio, el derecho a poseer o disfrutar de un domicilio o espacio físico en el que desenvolver la vida privada y familiar...".

14 Como acabamos de señalar, la insuficiencia "temporal" de alojamiento prácticamente se ha convertido en permanente, al haber aumentado considerablemente en los últimos años la población reclusa, haciéndose imprescindible la construcción de nuevos centros penitenciarios. Acerca de este problema de masificación que afecta a buena parte de nuestros establecimientos penitenciarios, vid. las estadísticas que sobre la población reclusa ofrece la Dirección General de Instituciones Penitenciarias (DGIP) del Ministerio del Interior, en el apartado "La gestión de cifras": $\{h t t p: / / w w w . m i r . e s /$ instpeni/gestion.htm\}. Con una actualización semanal y mensual, en esta página web se ofrecen datos sobre la población reclusa por Comunidades autónomas, por grupos de edad, por sexo, por tipología delictiva, por situación procesal-penal y por grado de tratamiento. En el mes de marzo de 2006 la población penitenciaria ascendía a un total de 62.426 internos.

Sobre el hacinamiento en las prisiones pueden consultarse algunos artículos periodísticos, como los del Diario el País, de 3 de marzo de 2002, "Mil nuevos presos al mes"; de 2 de julio de 2002, “Las cárceles españolas reciben 1000 presos más en los dos últimos meses”; de 4 de agosto de 2002, "133 presos se han suicidado en las cárceles españolas en los últimos seis años"; o de 11 de agosto de 2002, "Máxima tensión en las cárceles". En este último artículo, representantes del sindicato mayoritario de funcionarios de instituciones penitenciarias (ACAIP) ponen de manifiesto que la masificación de nuestras cárceles obliga a que haya dos internos por celda, cuando "la ley aconseja que haya uno para respetar el derecho a la intimidad". Esta situación da lugar a importantes problemas para acceder a servicios comunes, que por ley han de prestar los centros, así como también a problemas de seguridad y de mantenimiento del orden en las prisiones, aumentando la conflictividad".

De este problema de la saturación de nuestros centros penitenciarios en los últimos años, se ha hecho eco también el Defensor del Pueblo \{http// www.defensordelpueblo.es/ index.asp\}. Así, en el Informe del año 2001 remitido a las Cortes Generales (pp. 251-252), se reconoce cómo el incre- 